\title{
Administrando los Tributos en la Empresa, "casos de estudio usando la metodología constructiva"
}

\author{
Dr. Lucio VALDEIGLESIAS CABRERA ${ }^{43}$
}

\section{RESUMEN:}

El aspecto tributario es muy importante para la captación de los recursos económicos por parte del estado, su incidencia es importante en el crecimiento ordenado de los países y en beneficio de sus habitantes. Es por ello que presento a continuación, algunos temas relacionados al aspecto tributario. Estos son casos actuales y reales; los nombres de las empresas y de las personas que se indican son ficticios.

PALABRAS CLAVE: Instalación, Formalización, Empresa, Procedimientos, Notario, SUNAT.

\section{ABSTRACT:}

The tax aspect is very important to attract financial resources from the state, its impact is important in the orderly growth of the countries and for the benefit of its inhabitants. That is why we presented below, some issues related to the tax aspect. These are current and real cases; the names of the companies and individuals listed are fictitious.

KEYWORDS: Installation, Execution, Company Procedures, Notary, SUNAT.

\section{TEMA N ${ }^{\circ}$ 1: FORMALIZACIÓN DE UNA PERSONA NATURAL-CASO: "INSTALACIÓN DE UN NEGOCIO PASÓ A PASÓ”}

1. DATOS DEL CASO: El señor VÍCTOR FALCÓNI SÁLCEDO viene desarrollando la actividad de Comercialización de Soluciones de Hardware y Software como Persona Natural con Negocio desde Setiembre del 2001, desea constituir su empresa y formalizarse de esta manera como Persona Jurídica bajo la forma societaria de E.I.R.L. 
A lo largo de estos años ha venido trabajando con los siguientes proveedores de cómputo:

1. Intcomex Perú S.A.C.

2. Tech Data Perú S.A.C.

3. Grupo Deltron S.A.

4. Máxima Internacional S.A.

5. Nexsys del Perú S.A.C.

6. Ingram Micro S.A.

7. Paragón Internacional S.A.C.

8. Grupo MTI S.A.C.

9. Distribuidora Mesajil Hnos. S.A.C.

Es Partner/Socio de Negocios de las siguientes empresas internacionales:

1. Intel

2. Microsoft

3. Hewlett Packard

4. Lenovo/IBM

5. Cisco

6. Entre otros sus ventas anuales de los tres (3) últimos años han sido de:

- 2013 - S/. 290,000.00

- 2012 - $\mathrm{S} / .260,661.00$

- 2011 - S/.233,106.00

Sus principales clientes son:

1. Adolfo Everardo Nusser Dammert - Corredor de Seguros

2. CIDELCO S.A.C.

3. Constructora Chávez S.A.C.

4. Environmental Care S.A.C.

5. JV Contadores \& ASS S.A.C.

6. LEIS Maquinarias S.A.C.

7. MN \& Asociados Asesores y Corredores de Seguros S.A.

8. Network Security Services S.A.C.

9. Oftalmic Service S.A.C.

10. Ricardo Jesús Angulo Riedner - Corredor de Seguros

11. SALCOM S.A.C.

12. Sindicato de Empleados de la Empresa Telefónica del Perú S.A.A.

13. Termo encogibles del Perú S.A.

14. Ente otros.

Por lo que decidió formalizarse como persona jurídica. 


\section{PROCEDIMIENTOS PARA CONSTITUIRLO COMO PERSONA JURÍDICA}

Para la constitución de una Persona Jurídica se deben seguir los siguientes pasos:

I. SUNARP - Búsqueda de Índices y Reserva de Nombre: Estos procedimientos se podrán hacer en forma presencial en las oficinas de la SUNARP o en forma virtual a través de su portal de Publicidad Registral en Línea: https://enlinea.sunarp.gob.pe/interconexion/webapp/ extranet/Ingreso.do (para lo cual deberán registrarse previamente).

1. Búsqueda de Índices: Se realiza para verificar si existe o no otra empresa con la misma denominación. Se solicita cinco (05) opciones de nombres como máximo para la búsqueda de nombre de la empresa, la demora es generalmente de un (01) día útil y la respuesta es vía correo electrónico.

Si la búsqueda se realiza en las oficinas de la SUNARP el costo será de S/. 5.00 por cada opción de nombre, si se realiza a través del portal por S/. 5.00 se podrá verificar hasta un máximo de cinco opciones de nombre.

2. Reserva de Nombre: Cuando la SUNARP le haya brindado la respuesta indicando que la opción de nombre o una de las cinco opciones de nombre está libre (Anexo 1), entonces deberá hacer la Reserva de Nombre, para lo cual deberá brindar la siguiente información:

- Del solicitante:

- Documento de Identidad

- Tipo de participación en el proceso de constitución o modificación del estatuto de la persona jurídica.

- Correo electrónico.

- Dirección completa.

- Denominación completa, y si fuese el caso denominación abreviada de la persona jurídica.

- Tipo de persona jurídica propuesta.

- Domicilio de la persona jurídica (ciudad).

- Integrantes: Nombre completo, Documento de identidad.

- El costo de la Reserva de Nombre es de S/. 18.00 y la vigencia son de 30 días calendario, pasado ese tiempo ese nombre queda libre para la constitución de empresa de cualquier otro ciudadano.

- Solo se podrá realizar el trámite de Constitución de empresa hasta antes de los cuatro (04) días útiles de la fecha de vencimiento de la reserva de nombre. 
II. Centro MAC - Mejor Atención al Ciudadano: Para la constitución de la persona jurídica, se debe acercar al Centro MAC de acuerdo a la ubicación del domicilio fiscal:

- MAC Plaza Norte: Constituye empresas con domicilio fiscal en Lima Metropolitana.

- MAC Callao y MAC Ventanilla: Constituye empresas con domicilio fiscal en la Región Callao.

En los Centros MAC se puede constituir las siguientes modalidades empresariales: E.I.R.L., S.R.L., S.A.C. o S.A.

Los pasos a seguir son:

1. Presentar la Reserva de Preferencia Registral - Registro de Personas Jurídicas.

2. Presentar dos copias (02) copias del DNI de los socios (actualizado, vigente y sin deuda en ONPE), si él o los socios son extranjeros presentar el Carné de Extranjería y/o Pasaporte con autorización para firmar contratos. En caso de que alguno de los socios sea casado(a), deberá adjuntar dos (02) copias del DNI del cónyuge. No se aceptan DNI vencidos. Entre cónyuges NO pueden ser socios porque forma parte de una sociedad conyugal (Artículo $315^{\circ}$ Código Civil), salvo que se hayan casado bajo el régimen de separación matrimonial.

3. En caso los intervinientes sean mayores de 70 años, deberá presentar Certificado Médico, expedido por Médico Geriatra o Psicólogo, expedido por MINSA (Ministerio de Salud) o ESSALUD que señale que la persona "ESTA EN PLENO USO DE SUS FACULTADES MENTALES".

4. Para la descripción de la actividad económica de la empresa, si el objeto social es muy extenso es recomendable presentarlo impreso y en USB para agilizar la atención. (En MAC se desarrolla el Acto Constitutivo con una de las seis notarías afiliadas, que es designada según el horario que el cliente indique para la reunión).

5. El Centro MAC cuenta con un módulo del Banco de la Nación donde puede realizar el detalle del aporte de Capital Social (dinero, bienes o ambos):

Mínimo S/. 1,000.00 (Un mil Nuevos Soles).

Máximo S/. 28,000.00 (Veintiocho mil Nuevos Soles). 
- Bienes Muebles

Deberá consignar marca, modelo, serie y valor de bien mediante una declaración simple, NO se aceptan vehículos, mercaderías o inmuebles. Si aporta en Bienes el (la) cónyuge deberá firmar la Escritura Pública.

- Dinero

Deberá ser en efectivo, moneda nacional y se deberá depositar el aporte en el Banco de la Nación, en una cuenta transitoria, solo para efectos de constitución, previa elaboración del Certificado de Depósito (el forma se lo brindan dentro del Centro MAC). No se aceptan transferencias bancarias.

6. Los formatos de Declaración Jurada y Ficha de Solicitud de Constitución de Empresa, serán entregados al momento de realizar la reserva, los mismos que deberán estar debidamente llenados al momento de presentarse al Módulo de Atención, para efectuar el trámite de constitución.

7. La duración del trámite de constitución de empresa en el Centro MAC es de aproximadamente una semana, días más o días menos, dependiendo de los casos. La empresa se da por constituida cuando al último día le entregan su número de RUC, Clave SOL y copia de acta registral de la empresa.

Costos aproximados Servicios Notariales y Registrales: entre S/. 250.00 a S/. 330.00 nuevos soles, dependiendo de la notaría seleccionada y el monto del capital social.

Todo el trámite es estrictamente personal por el titular o los socios, NO se admiten terceros.

III. SERVICIOS NOTARIALES: Debe acercarse a la notaria seleccionada en la fecha y hora acordada en el Centro MAC para la firma de la Escritura Pública, para ello deberá llevar:

1. Constancia del depósito realizado en el Banco de la Nación por Servicios Notariales y Registrales.

2. Reserva de Preferencia Registral - Registro de Personas Jurídicas emitida por la SUNARP.

3. Copia del DNI del titular o socios, en caso alguno de ellos fuera casado, copia del DNI del (la) cónyuge. 
Una vez presentados estos documentos, la notaría elaborará la Escritura Pública, la misma que deberá ser firmada por el titular o socios, y en caso alguno de ellos fuera casado, su (sus) respectivo(a) cónyuge.

En el transcurso de 3 a 5 días útiles la notaría entregará el Testimonio de Constitución de Empresa registrada en la SUNARP.

IV. SUNAT: Para concluir con la constitución de la empresa, se dirigirá a la SUNAT para solicitar el RUC llevando los siguientes documentos:

1. Original y dos (02) copias del Documentos de Identidad vigente del titular o socios.

2. Recibo de agua, luz, telefonía fija o televisión por cable, cuya fecha de vencimiento de pago se encuentre comprendida en los dos (02) últimos meses, en original y copia. Si el domicilio fiscal pertenece a una persona natural o jurídica deberán presentar el formulario de Autorización de Uso de Documento de Tercero para Declarar Domicilio Fiscal o Establecimiento entregado por la SUNAT o bajado del portal institucional de la SUNAT.

3. Copia Literal Certificada emitida por los Registros Públicos con una antigüedad no mayor a 30 días calendarios.

Una vez que se registre toda la información y se haya creado el RUC de la empresa, se le hará entrega del CIR - Comprobante de Información Registrada 3119 -1 y el sobre conteniendo la Clave SOL con los datos de usuario y contraseña para poder ingresar al portal de la SUNAT y registrar la información mensual y anual de las operaciones que realiza la empresa a través del PDT y del PLAME (en caso de tener personal a cargo en planilla), así como a otras operaciones.

\section{TEMA N N $^{\circ}$ : COMO SOLUCIONAR PROBLEMAS TRIBUTARIOS ANTE LA SUNAT - CASO: COBRANZA COACTIVA POR LA SUNAT}

1. Situación Actual: La Empresa Milk Dent SAC, con número de RUC 20433460597, se encuentra dentro del Rubro de venta mayorista de productos dentales, lleva su contabilidad de forma computarizada. Se verifico en la página virtual SUNAT, sobre una cobranza coactiva de S/. S/.80, 274, actualizada al 29 de Octubre del 2014.

2. Acciones efectuadas: El consultor tributario con fecha El día 25 de Noviembre 2014, se entrevistó con el Contador General de la Empresa, 
cual fue el motivo de la deuda, indico que a pesar de que los impuestos han sido declarados y pagados en la fecha oportuna, el problema radica en los tributos retenidos (Rentas de 4ta y 5ta categoría), que no se pagaron.

Al ser tributos retenidos a terceros, según el Artículo178 del Código Tributario "INFRACCIONES RELACIONADAS CON EL CUMPLIMIENTO DE LAS OBLIGACIONES TRIBUTARIAS" en el inciso 4, indica: "No pagar dentro de los plazos establecidos los tributos retenidos o percibidos", debiendo la empresa pagar el monto indicado más los intereses y la multa (Articulo 181)

Según el Artículo 180 del Código Tributario, el monto de la sanción correspondiente por el no pago de estos tributos es del $100 \%$ de la UIT, al ser notificado y habiendo sido emitida la resolución de multa correspondiente, según el Artículo 179, la empresa no será beneficiada con ningún incentivo tributario.

El monto que debe pagar la entidad se calcula de la siguiente manera:

Multa $=100 \%$ UIT $=$ S/. 3,800.00 (año 2014)

Fecha de la Infracción $=11$ febrero 2014

Fecha de Subsanación $=15$ Noviembre 2014

Total de Días $=277$ (calendario)

$\mathrm{TIM}=12 \%$, Interés moratorio diario $=0.04 \%$

Total Intereses $=11.08 \%$

Actualización de la deuda Multa $=$ S/. 421.04

Actualización de la deuda Tributo $=\mathrm{S} / .8,893.36$

Total a pagar $=$ Tributos + Multa + Intereses $=$ S/. 93,388

Medios de Pago:Al ser tributos retenidos a terceros, según el artículo 36 indicas: "APLAZAMIENTO Y/O FRACCIONAMIENTO DE DEUDAS TRIBUTARIAS (40) Se puede conceder aplazamiento y/o fraccionamiento para el pago de la deuda tributaria con carácter general, excepto en los casos de tributos retenidos o percibidos, de la manera que establezca el Poder Ejecutivo."

Por lo que la única alternativa de pago es hacerlo en efectivo.

3. Situación Final: Con fecha 15 de Noviembre la Gerencia General de la Empresa en coordinación con el Contador General determino pagar en efectivo a través del Banco de la Nación, a la SUNAT la suma de S/.93, 388. Con el cual quedo solucionado el aspecto tributario de la empresa Milk Dent S.A. 


\section{CONCLUSIONES}

- Es importante que una persona con negocio tienda a seguir escalando en los negocios, esto hace que requiera conocer las formas de constituir una empresa y los efectos tributarios que tendrá dicha empresa a partir de la obtención del Registro Único del Contribuyente - RUC.

- El pequeño empresario debe entender que los impuestos deben ser pagados en su oportunidad y cuanto corresponde pagar.

\section{REFERENCIA BIBLIOGRÁFICA}

1. Decreto Legislativo $N^{\circ} 943$ - Registro Único del Contribuyente - RUC.

2. Ley del Impuesto a la Renta D.S. 179-2004-EF (actualizado al 15/03/2007).

3. Ley Impuesto General a las Ventas y Selectivo al Consumo D.S.055-99EF del 15/04/1999 y su Reglamento.

4. Texto único ordenado del Código Tributario Decreto Supremo No 133 2013-EF del 22/06/2013 - EF. 